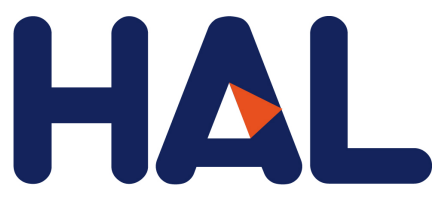

archives-ouvertes

\title{
Modified approach of the anterior commissure for transoral cordectomy in case of difficult exposure: a surgical innovation
}

Alexia Mattei, Carole Boulze, Laure Santini, Matthieu Le Flem, Patrick Dessi, Nicolas Fakhry, Antoine Giovanni

\section{To cite this version:}

Alexia Mattei, Carole Boulze, Laure Santini, Matthieu Le Flem, Patrick Dessi, et al.. Modified approach of the anterior commissure for transoral cordectomy in case of difficult exposure: a surgical innovation. European Archives of Oto-Rhino-Laryngology, Springer Verlag, 2020, 277, pp.301-306. 10.1007/s00405-019-05692-2 . hal-02476110

\section{HAL Id: hal-02476110 \\ https://hal.archives-ouvertes.fr/hal-02476110}

Submitted on 29 Feb 2020

HAL is a multi-disciplinary open access archive for the deposit and dissemination of scientific research documents, whether they are published or not. The documents may come from teaching and research institutions in France or abroad, or from public or private research centers.
L'archive ouverte pluridisciplinaire HAL, est destinée au dépôt et à la diffusion de documents scientifiques de niveau recherche, publiés ou non, émanant des établissements d'enseignement et de recherche français ou étrangers, des laboratoires publics ou privés. 


\section{European Archives of Oto-Rhino-Laryngology \\ Modified approach of the anterior commissure for transoral cordectomy in case of difficult exposure: a surgical innovation \\ --Manuscript Draft--}

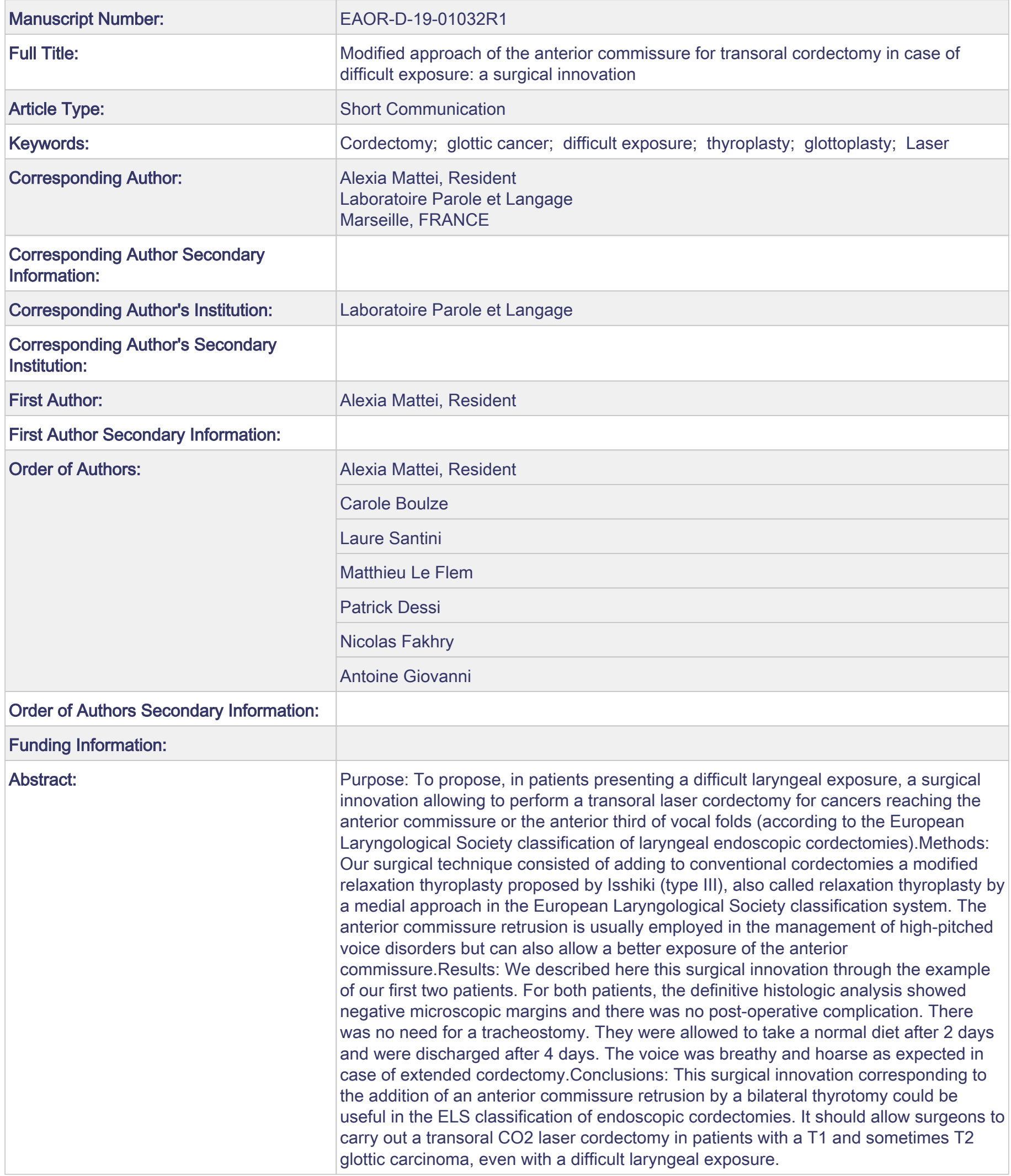




\begin{abstract}
.
Purpose: To propose, in patients presenting a difficult laryngeal exposure, a surgical innovation allowing to perform a transoral laser cordectomy for cancers reaching the anterior commissure or the anterior third of vocal folds (according to the European Laryngological Society classification of laryngeal endoscopic cordectomies).
\end{abstract}

Methods: Our surgical technique consisted of adding to conventional cordectomies a modified relaxation thyroplasty proposed by Isshiki (type III), also called relaxation thyroplasty by a medial approach in the European Laryngological Society classification system. The anterior commissure retrusion is usually employed in the management of high-pitched voice disorders but can also allow a better exposure of the anterior commissure.

Results: We described here this surgical innovation through the example of our first two patients. For both patients, the definitive histologic analysis showed negative microscopic margins and there was no post-operative complication. There was no need for a tracheostomy. They were allowed to take a normal diet after 2 days and were discharged after 4 days. The voice was breathy and hoarse as expected in case of extended cordectomy.

Conclusions: This surgical innovation corresponding to the addition of an anterior commissure retrusion by a bilateral thyrotomy could be useful in the ELS classification of endoscopic cordectomies. It should allow surgeons to carry out a transoral $\mathrm{CO} 2$ laser cordectomy in patients with a $\mathrm{T} 1$ and sometimes $\mathrm{T} 2$ glottic carcinoma, even with a difficult laryngeal exposure.

\title{
KEYWORDS
}

Cordectomy, glottic cancer, difficult exposure, thyroplasty, glottoplasty, laser. 


\section{INTRODUCTION}

The European Laryngological Society (ELS) proposed in 2000 a classification of laryngeal endoscopic cordectomies [1], so as to reach better uniformity concerning the depth and extent of resection in cordectomy procedures and to offer reproducibility to allow relevant comparisons with the literature when publishing the results of cordectomies.

The initial classification described eight types of cordectomies:

- $\quad$ Type I: subepithelial;

- $\quad$ Type II: subligamental;

- Type III: transmuscular;

- Type IV: total cordectomy extending from the vocal process to the anterior commissure, the depth of the surgical margins reaches the internal perichondrium of the thyroid ala (which can also be included sometimes)

- $\quad$ Type $\mathrm{Va} / \mathrm{Vb} / \mathrm{Vc} / \mathrm{Vd}$ : extended cordectomy respectively encompassing the contralateral vocal fold and the anterior commissure, the arytenoid, the ventricle or the subglottis.

Then, in 2007, Remacle et al. [2] proposed a revision of this classification with addition of a type VI cordectomy for cancers of the anterior commissure, extended or not to one or both of the vocal folds, without infiltration of the thyroid cartilage. This corresponded to an anterior commissurectomy with bilateral anterior cordectomy.

This classification has been well received and is currently used by many authors [2]. However, surgeons sometimes have to face difficult exposure of the anterior commissure during direct laryngoscopy. This difficulty can be linked to the narrow angled and $\mathrm{V}$-shaped configuration of the thyroid alae (particularly in male patients) or to the petiole of the epiglottis frequently obstructing the visualization of the anterior commissure.

Our objective was to propose a surgical innovation allowing to perform a transoral laser cordectomy in these cases: the association of an anterior thyroplasty by a medial approach (anterior commissure retrusion analogue to a relaxation glottoplasty) in order to improve the anterior commissure exposure by impacting it from front to back.

\section{DESCRIPTION OF THE SURGICAL TECHNIQUE}

This surgical technique is indicated for cancer reaching the anterior commissure or the anterior third of vocal folds in patients presenting a difficult laryngeal exposure during direct laryngoscopy.

In this cancer location, the adequate technique according to ELS guidelines consists of a type Va or VI cordectomy, under general anaesthesia, with tracheal intubation [1,2]. Resection of the anterior commissure may include the subglottic mucosa and the cricothyroid membrane [3] because cancers of the anterior commissure tend to spread towards the lymphatic vessels of the subglottic area [4]. If the tumour is in close contact with the cartilage, an additional resection of the anterior angle of the thyroid cartilage is indicated [2].

In order to expose properly the anterior part of the vocal folds, different laryngoscopes and different positions including the sniffing position can be used [5,6]. A partial resection of the false vocal folds can also be achieved. Unfortunately, that is not always enough. In this case, an impaction of the anterior commissure from front to back can be useful and decided during the endoscopic procedure.

The surgical technique employed is identical to the modified relaxation (type III) thyroplasty proposed by Isshiki $[7,8]$ to release tension in the vocal folds by incising and depressing the anterior segment of the thyroid cartilage [9]. This procedure is called relaxation thyroplasty by a medial approach (anterior commissure retrusion) in the ELS classification system and is used in the management of high-pitched voice disorders.

A $4 \mathrm{~cm}$ horizontal median skin incision is carried out at the level of the middle of the thyroid cartilage, down through the platysma muscle, and superior and inferior subplatysmal flaps are raised. A midline vertical incision is made down to the perichondrium, separating the sub-hyoid muscles at the median raphe. Vertical incisions in the outer perichondrium with a cold blade then in the thyroid lamina with an oscillating saw are made $5 \mathrm{~mm}$ posterior to the anterior angle, from the top edge to the bottom edge. Cuts should stop just short of the inner perichondrium to avoid its injury. The anterior cartilage segment is then pushed into the larynx. This one can be kept in this position by an assistant surgeon maintaining the cartilage or with nylon sutures passing through the outer perichondrium or the thyroid ala. 
Then the transoral laser cordectomy can restart thanks to a better exposure (Fig. 1). At its end, the anterior cartilage segment is replaced to its initial location where it is secured in position by two or three nylon sutures on each side, passing through the cartilage laminas and the outer perichondrium. If the cartilage is too ossified, small holes are drilled to pass the thread. Then muscular and cutaneous layers are also sutured in the usual way, using a drainage removed the day after.

It is important to emphasize that, unlike an external cordectomy, the mucosal membrane is not open during cervicotomy here.

To date we performed this surgical technique in two patients.

The first case was a 55-year-old man, without major medical background except an important smoking, who presented a squamous cell carcinoma reaching the two anterior thirds of left vocal fold and the anterior commissure (Fig. 2). Larynx was still mobile and there was no metastasis according to CT scan. Before surgery, the lesion was classified cT1bNOM0 according to TNM classification. The chosen treatment was a type Va transoral laser cordectomy. If cordectomy was not possible, a partial laryngectomy (hemilaryngectomy) or a radiotherapy would have been necessary. During surgery, the Bouchayer laryngoscope allowed surgeon to expose correctly the posterior part of vocal folds only. The laryngoscope was changed for a Dedo's model which allowed the surgeon to perform the cordectomy almost entirely, with the help of a partial resection of the two ventricular bands. However, a proper resection of the anterior commissure was not possible with an isolated transoral approach. The addition of a relaxation thyroplasty by a medial approach allowed to complete the resection with negative macroscopic margins. The approach for a tracheotomy was prepared but finally there was no need to use it.

The second case was a 68-year-old man with a history of coronary artery disease with aspirin treatment, arrhythmia and weaned smoking. He presented a squamous cell carcinoma on the anterior third of the left vocal fold, which was still mobile. The lesion was classified cT1aNOM0 and a type Va cordectomy was again indicated. The same procedure was achieved, extended to the anterior third of the right vocal fold due to the per-operatory findings.

For both patients, the definitive histologic analysis showed negative microscopic margins and there were no postoperative complications. They were allowed to take a normal diet after 2 days (initially mixed, cold or warm feeding without liquids to avoid pain, bleeding and aspirations).

They were discharged after 4 days. Eight weeks after they had a control endoscopy with multiple biopsies which were all negative. The first patient developed an anterior synechia without dyspnea (Fig. 3). Both patients presented post-operatively a hoarse voice, notably because of the involvement of false vocal folds and arytenoids during phonation, but this was expected given the need for a wide cordectomy (Online Resource 1).

\section{DISCUSSION}

This surgical innovation seems to be a useful way to perform an effective treatment in patients presenting an indication of laryngeal endoscopic cordectomies but having a difficult laryngeal exposure. This technique had so far never been described to our knowledge. Other teams had already described combined endoscopic and external approaches but the endoscopic approach was then used mainly to delimit the margins of the tumour with excision performed externally [10].

This difficult exposure is usually verified during the pretherapeutic set up often including direct laryngoscopy for biopsies. In cases where the difficulty is uncertain, prior consent of the patient is obviously necessary to switch to an open approach if necessary (after discussing other possibilities such as radiotherapy).

This technical variant can help surgeons obtain negative margins, which is very important in this location since the anterior commissure is the laryngeal subsite that is more frequently at risk to give rise to local treatment failures $[2,11,12]$. The anterior commissure is characterized by the lack of perichondrium on the inner surface of the thyroid cartilage, even if the anterior Broyle's ligament should also be a solid barrier. This anatomy feature facilitates the spread of carcinoma into the thyroid cartilage and beyond the laryngeal framework. The other particularity of this location is that the supraglottic, glottic and subglottic compartments of the larynx are very close from one to another so that even very small tumors can gain access to the lymphatic system of the supraglottis and the subglottis [13]. Moreover the laryngologist has to perform a resection providing a good specimen for histological assessment and not just a tissue vaporization [14]. For these reason, transoral laser resection has repeatedly been discouraged for anterior commissure carcinoma, but mainly because of inadequate exposure. 
Our protocol can also be used for a second treatment in case of positive surgical margins. Bertino et al. [15] showed a significant decline in the disease free survival rate for patients with one or more positive superficial margins plus close deep margin (40\% vs $60 \%$ ), so as Charbonnier et al. [16]. Peretti et al. [17] reported the importance of a second treatment in this situation even if the percentage of histologically confirmed neoplastic tissue in the specimen of the laser re-resection can be low (18\% for Bertino et al. [15]), probably due to small specimen size, thermal effects induced by the laser and/or tissue retraction [18]. The most generally recommended attitude is, in case of macroscopically negative but microscopically positive margins, a control endoscopy at 8-10 weeks with biopsies [17-19]. The interval allows the larynx to heal and provides histologically reliable results. Having an optimal laryngeal exposure is even more important for these patients.

The advantage of a transoral cordectomy treatment is the reduction of convalescence and of the risk of sequelae. If it was impossible to carry out a transoral laser approach, these patients would have been treated with external cordectomy, open partial laryngectomy or radiotherapy. But avoiding tracheotomy or feeding tube can facilitate a quick, safe recovery of swallowing [20]. Patients after endoscopic laser CO2 cordectomy, compared to laryngofissure open cordectomy, seem to present better voice quality, notably for Fo range, phonation time and intensity [21]. The amount of the excised vocal fold tissue, often slightly larger in case of open cordectomy, could account for it. Moreover, due to the mucosal break-in performed in external cordectomy and partial laryngectomy, a level difference can exist between the neocord and the contralateral vocal fold with an increase of dysphonia [21]. Some authors claim no differences in voice quality with or without radiotherapy while others maintain that the radiotherapy is better. But this therapeutic strategy presents a long-term risk of various post-radiation complications mainly due to fibrotic effects.

On a cost-effective point of view, cordectomy is cheaper than others therapeutic strategy because of a shorter hospitalization and a sooner return to work [22,23].

Resection using fiber-guided lasers like KTP or CO2 wave-guide with a handpiece [24], with a rigid endoscope, is also possible in these situations but, if these lasers can reach areas poorly visualized via a microscope, they do not necessarily allow to loosen and smooth the tissues to better expose the limits of excision.

These results are obviously limited by the fact that we currently have only 2 cases in our series, which is not enough to evaluate the risks, complications and the oncologic security of the procedure. More patients will be necessary to confirm the safety and feasibility of this approach. The risk of cancer extrusion outside the larynx in case of recurrence theoretically has no reason to be higher than that incurred with laryngofissure open cordectomies (moreover in cases where the inner perichondrium can be respected) but it has to be carefully monitored in the event of a bad oncological evolution (with CT scan in particular). We also have to keep in mind that this technique is not recommended for laryngeal cancer that is not accessible via a transoral route, for example if CT examination reveals a possible tumoral infiltration through the thyroid cartilage. In this case, others techniques can be indicated, for example open partial horizontal laryngectomies [25]. Our surgical innovation allows surgeons to perform an endoscopic cordectomy despite difficult exposure when it is indicated but it does not change its indications.

Going forward, if the safety and efficacy of this surgical innovation is then confirmed in a larger number of patients, its mention in the ELS classification could offer reproducibility to the laryngologists to allow relevant comparisons when presenting the results of cordectomies.

\section{CONCLUSION}

The surgical innovation corresponding to the addition of an anterior commissure retrusion by a bilateral thyrotomy could be a useful modified approach in the ELS classification of endoscopic cordectomies. It should allow surgeons to carry out a transoral $\mathrm{CO} 2$ laser cordectomy in patients with a $\mathrm{T} 1$ and sometimes $\mathrm{T} 2$ glottic carcinoma, even with a difficult laryngeal exposure. 


\section{REFERENCES}

1. Remacle M, Eckel HE, Antonelli A, Brasnu D, Chevalier D, Friedrich G, Olofsson J, Rudert HH, Thumfart W, de Vincentiis M, Wustrow TP (2000) Endoscopic cordectomy. A proposal for a classiWcation by the Working Committee, European Laryngological Society. Eur Arch Otorhinolaryngol 257(4):227-231.

2. Remacle M, Van Haverbeke C, Eckel H, Bradley P, Chevalier D, Djukic V, De Vicentiis M, Friedrich G, Olofsson J, Peretti G, Quer M, Werner J (2007) Proposal for revision of the European Laryngological Society classification of endoscopic cordectomies. Eur Arch Otorhinolaryngol 264:499-504. https://doi.org/10.1007/s00405-007-0279-z.

3. Eckel HE, Thumfart WF (1992) Laser surgery for the treatment of larynx carcinomas: indications, techniques and preliminary results. Ann Otol Rhinol Laryngol 101(2Pt1):113-118.

4. Kirschner JA (1984) Invasion of the framework by laryngeal cancer. Surgical and radiological implications. Acta Otolaryngol (Stockh) 97(5-6):392-397.

5. Hochman II, Zeitels SM, Heaton JT. Analysis of the forces and position required for direct laryngoscopic exposure of the anterior vocal folds. Ann Otol Rhinol Laryngol. août 1999;108(8):715- 24.

6. Kitamura Y, Isono S, Suzuki N, Sato Y, Nishino T. Dynamic interaction of craniofacial structures during head positioning and direct laryngoscopy in anesthetized patients with and without difficult laryngoscopy. Anesthesiology. déc 2007;107(6):875-83.

7. Isshiki N (1989) Phonosurgery. Theory and practice. Springer-Verlag,Tokyo.

8. Isshiki N, Taira T, Tanabe M (1988) Surgical treatment for vocal pitch disorders. In: Fujimura O (ed) Vocal physiology: voice productions, mechanisms and functions. Raven Press, New York, pp 449-58.

9. Remacle M, Matar N, Verduyckt I, Lawson G (2010) Relaxation thyroplasty for mutational falsetto treatment. Ann Otol Rhinol Laryngol 119(2):105-9. https://doi.org/10.1177/000348941011900207.

10. Conticello S, Biondi S, Ferlito S (1999) Indications and results of fronto-lateral laryngectomy using a combined endolaryngeal and external approach. Eur Arch Otorhinolaryngol 256(8):373-7.

11. Eckel HE (2001) Local recurrences following transoral laser surgery for early glottic carcinoma: frequency, management and outcome. Ann Otol Rhinol Laryngol 110:7-15.

12. Hoffmann C, Hans S, Sadoughi B, Brasnu D (2016) Identifying outcome predictors of transoral laser cordectomy for early glottic cancer. Head Neck 38 Suppl 1:E406-11. https://doi.org/10.1002/hed.24007.

13. Sprinzl GM, Eckel HE, Sittel C, Potoschnig C, Koebke J (1999) Morphometric measurements of the cartilaginous larynx: an anatomic correlate of laryngeal surgery. Head Neck 21:743-750.

14. Mahieu HF, Patel P, Annyas AA, van der Laan T (1994) Carbon dioxide laser vaporization in early glottic carcinoma. Arch Otolaryngol Head Neck Surg 120(4):383-387.

15. Bertino G, Degiorgi G, Tinelli C, Cacciola S, Occhini A, Benazzo M (2015) CO2 laser cordectomy for T1T2 glottic cancer: oncological and functional long-term results. Eur Arch Otorhinolaryngol 272(9):2389-95. https://doi.org/10.1007/s00405-015-3629-2.

16. Charbonnier Q, Thisse AS, Sleghem L, Mouawad F, Chevalier D, Page C, Mortuaire G (2016) Oncologic outcomes of patients with positive margins after laser cordectomy for T1 and T2 glottic squamous cell carcinoma. Head Neck 38(12):1804-1809. https://doi.org/10.1002/hed.24518.

17. Peretti G, Piazza C, Cocco D et al (2010) Transoral CO2 laser treatment for Tis-T3 glottic cancer: the University of Brescia experience on 595 patients. Head Neck 32:977-983.

18. Michel J, Fakhry N, Duflo S, Lagier A, Mancini J, Dessi P, Giovanni A (2011) Prognostic value of the status of resection margins after endoscopic laser cordectomy for T1a glottic carcinoma. Eur Ann Otorhinolaryngol Head Neck Dis. 128(6):297-300. https://doi.org/10.1016/j.anorl.2011.05.006. 
19. Jackel MC, Ambrosch P, Martin A, Steiner W (2007) Impact of re-resection for inadequate margins on the prognosis of upper aerodigestive tract cancer treated by laser microsurgery. Laryngoscope 117:350-6.

20. Landolfo V, Gervasio CF, Riva G, Garzaro M, Audisio R, Pecorari G, Albera R (2018) Prognostic role of margin status in open and $\mathrm{CO} 2$ laser cordectomy for T1a-T1b glottic cancer. Braz J Otorhinolaryngol 84(1):74-81. https://doi.org/10.1016/j.bjorl.2016.11.006.

21. Lachowska M, Osuch-Wójcikiewicz E, Bruzgielewicz A (2011) Voice evaluation following endoscopic laser $\mathrm{CO}(2)$ cordectomy and conventional cordectomy. Arch Med Sci 7(1):143-53. https://doi.org/10.5114/aoms.2011.20621.

22. Brandenburg JH (2001) Laser cordotomy versus radiotherapy: an objective cost analysis. Ann Otol Rhinol Laryngol 110:312-8.

23. Diaz-de-Cerio P, Preciado J, Santaolalla F, Sanchez-del-Rey A (2013) Cost-minimisation and costeffectiveness analysis comparing transoral $\mathrm{CO} 2$ laser cordectomy, laryngofissure cordectomy and radiotherapy for the treatment of T1-2, N0, M0 glottic carcinoma Eur Arch Otorhinolaryngol 270:11811188. https://doi.org/10.1007/s00405-012-2139-8.

24. Remacle M, Arens C, Eldin MB, Campos G, Estomba CC, Dulguerov P, et al. Laser-assisted surgery of the upper aero-digestive tract: a clarification of nomenclature. A consensus statement of the European Laryngological Society. Eur Arch Otorhinolaryngol. 2017;274(10):3723- 7.

25. Succo G, Peretti G, Piazza C, Remacle M, Eckel HE, Chevalier D, Simo R, Hantzakos AG, Rizzotto G, Lucioni M, Crosetti E, Antonelli AR (2014) Open partial horizontal laryngectomies: a proposal for classification by the working committee on nomenclature of the European Laryngological Society. Eur Arch Otorhinolaryngol 271(9):2489-96. 


\section{CAPTIONS}

Fig. 1 Surgical innovation: an anterior commissure retrusion by a bilateral thyrotomy allowing a better exposure of the anterior commissure during the direct laryngoscopy ( $a$ : before and $b$ : after the thyroplasty)

Fig. 2 Intra-operative findings (a) and CT scan before surgery (b) for patient 1

Fig. 3 Videolaryngoscopy (a) and CT scan (b) one year after surgery for patient 1

Online Resource 1 Patient 1's voice one year after treatment: a hoarse and breathy but perfectly intelligible voice 


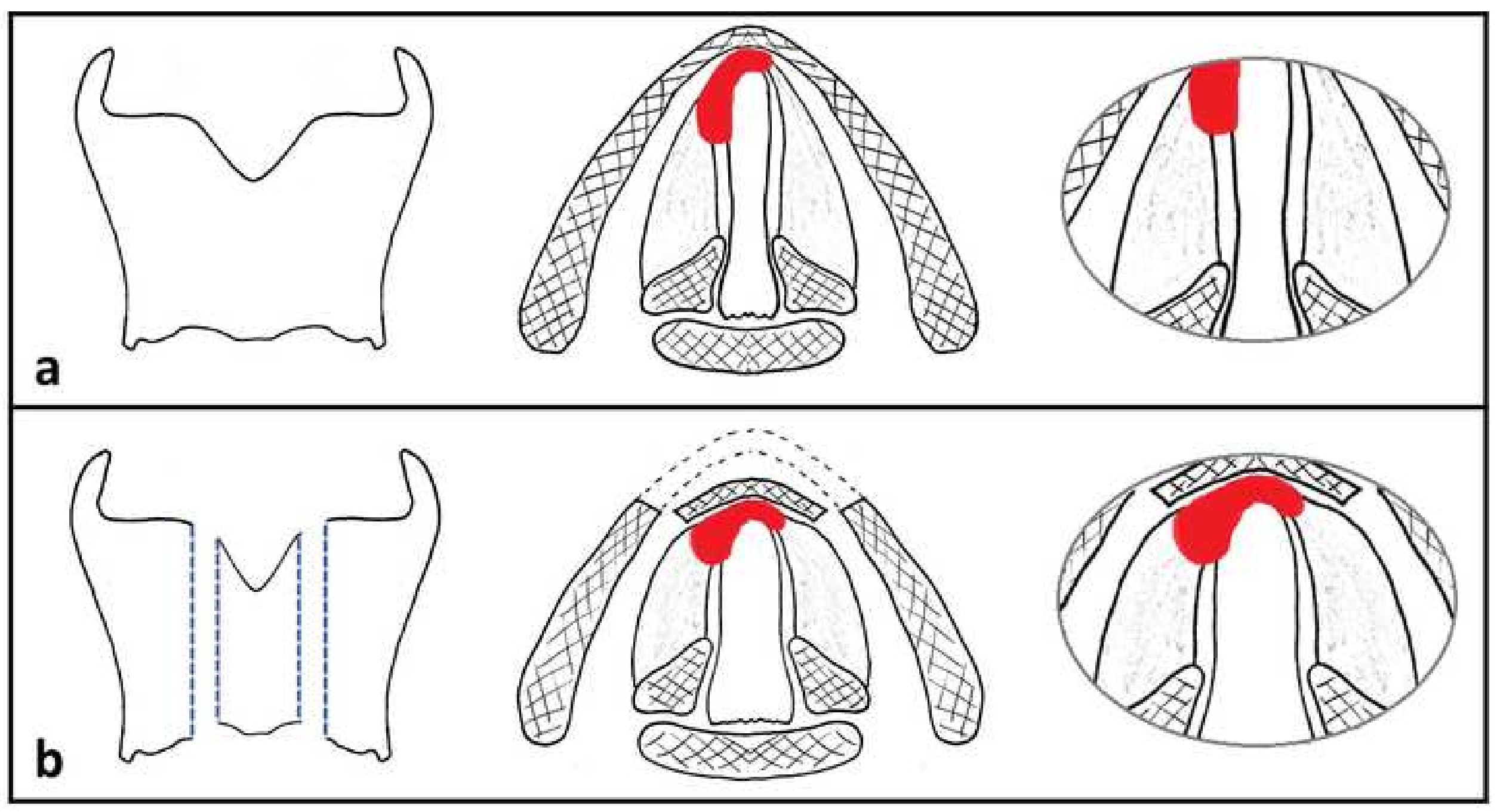




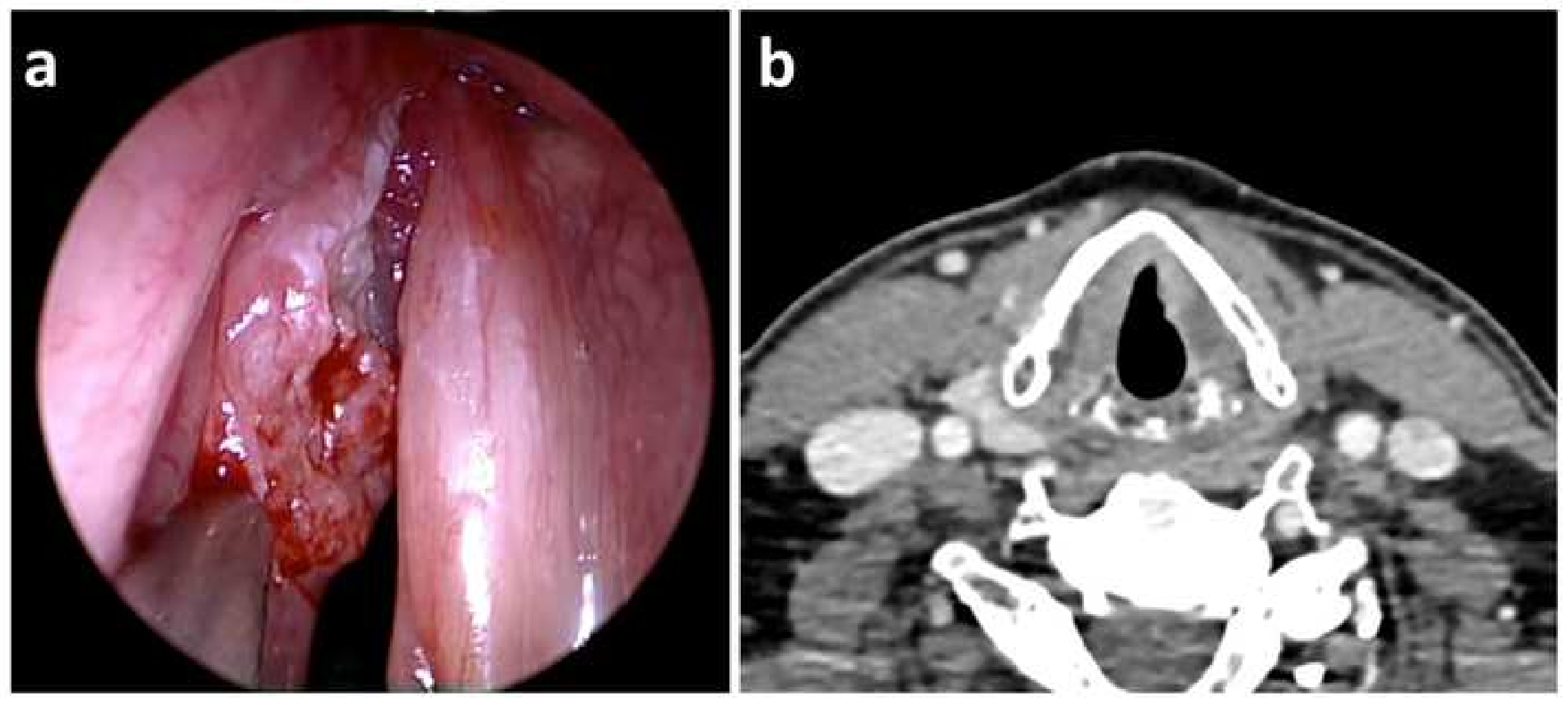




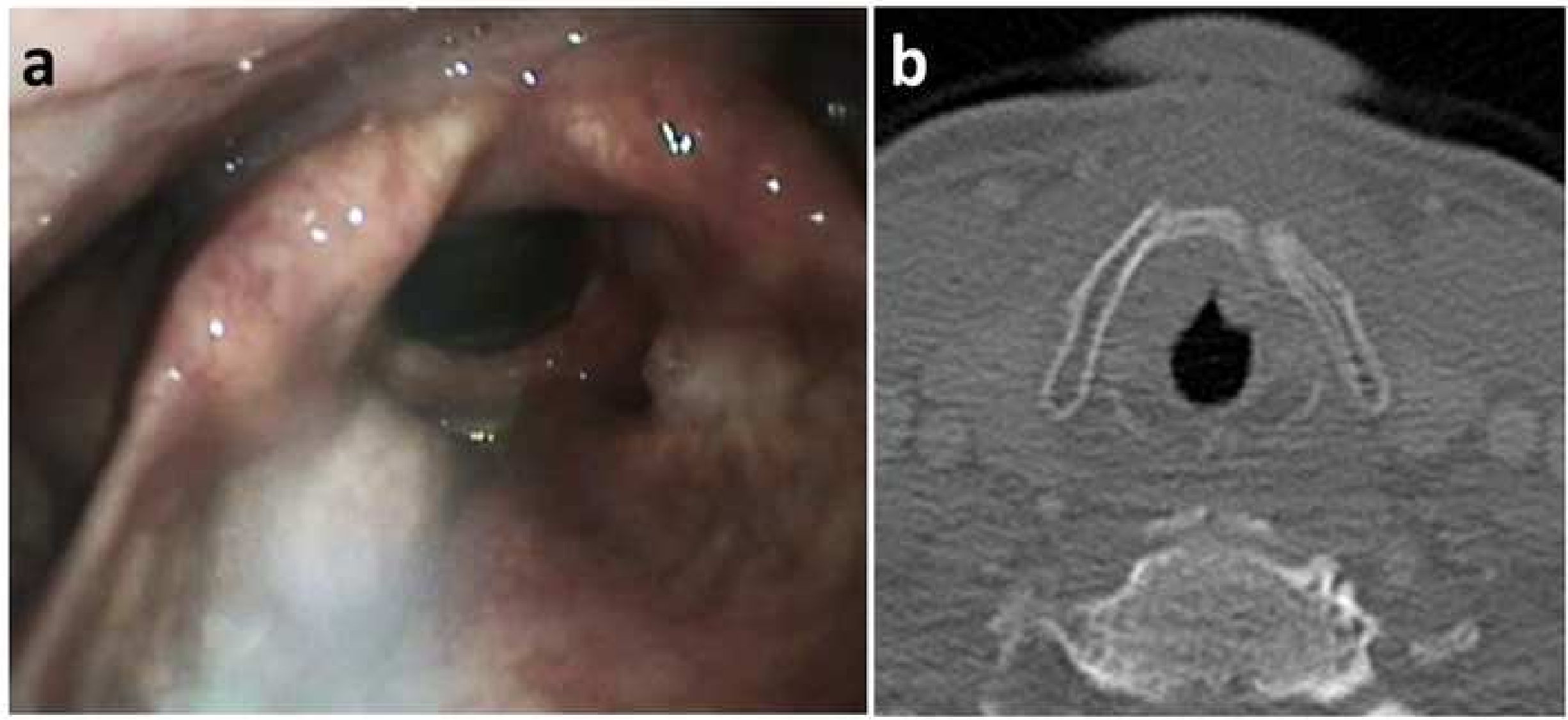


Electronic Supplementary Material

\section{Click here to access/download \\ Electronic Supplementary Material ESM_1.mp4}

